\title{
Article \\ N-3-Hydroxy Dodecanoyl-DL-homoserine Lactone (OH-dDHL) Triggers Apoptosis of Bone Marrow-Derived Macrophages through the ER- and Mitochondria-Mediated Pathways
}

\author{
Kyungho Woo ${ }^{1}$, Dong Ho Kim ${ }^{1}$, Man Hwan Oh ${ }^{2}$, Ho Sung Park ${ }^{1}\left(\mathbb{D}\right.$ and Chul Hee Choi ${ }^{1, *}$ \\ 1 Department of Microbiology and Medical Science, Chungnam National University School of Medicine, \\ Daejeon 35015, Korea; khwoo1991@gmail.com (K.W.); kiyou1553@gmail.com (D.H.K.); \\ 89hos701@gmail.com (H.S.P.) \\ 2 Department of Microbiology, Dankook University, Cheonan 31116, Korea; yy1091kwak@gmail.com \\ * Correspondence: choich@cnu.ac.kr; Tel.: +82-42-580-8246
}

Citation: Woo, K.; Kim, D.H.; Oh, M.H.; Park, H.S.; Choi, C.H. N-3-Hydroxy Dodecanoyl-DLhomoserine Lactone (OH-dDHL) Triggers Apoptosis of Bone Marrow-Derived Macrophages through the ER- and Mitochondria-Mediated Pathways. Int. J. Mol. Sci. 2021, 22, 7565. https://doi.org/10.3390/ ijms22147565

Academic Editor: Stephen Bustin

Received: 21 June 2021

Accepted: 13 July 2021

Published: 15 July 2021

Publisher's Note: MDPI stays neutral with regard to jurisdictional claims in published maps and institutional affiliations.

Copyright: (c) 2021 by the authors. Licensee MDPI, Basel, Switzerland. This article is an open access article distributed under the terms and conditions of the Creative Commons Attribution (CC BY) license (https:/ / creativecommons.org/licenses/by/ $4.0 /)$.

\begin{abstract}
Quorum sensing of Acinetobacter nosocomialis for cell-to-cell communication produces $N$ 3-hydroxy dodecanoyl-DL-homoserine lactone (OH-dDHL) by an AnoR/I two-component system. However, OH-dDHL-driven apoptotic mechanisms in hosts have not been clearly defined. Here, we investigated the induction of apoptosis signaling pathways in bone marrow-derived macrophages treated with synthetic $\mathrm{OH}$-dDHL. Moreover, the quorum-sensing system for virulence regulation was evaluated in vivo using wild-type and anoI-deletion mutant strains. OH-dDHL decreased the viability of macrophage and epithelial cells in dose- and time-dependent manners. OH-dDHL induced $\mathrm{Ca}^{2+}$ efflux and caspase-12 activation by ER stress transmembrane protein (IRE1 and ATF6a p50) aggregation and induced mitochondrial dysfunction through reactive oxygen species (ROS) production, which caused cytochrome c to leak. Pretreatment with a pan-caspase inhibitor reduced caspase- $3,-8$, and -9 , which were activated by OH-dDHL. Pro-inflammatory cytokine and paraoxonase-2 (PON2) gene expression were increased by OH-dDHL. We showed that the anoIdeletion mutant strains have less intracellular invasion compared to the wild-type strain, and their virulence, such as colonization and dissemination, was decreased in vivo. Consequently, these findings revealed that $\mathrm{OH}-\mathrm{dDHL}$, as a virulence factor, contributes to bacterial infection and survival as well as the modification of host responses in the early stages of infection.
\end{abstract}

Keywords: A. nosocomialis; quorum sensing; apoptosis; OH-dDHL; virulence

\section{Introduction}

Several Acinetobacter species, such as A. baumannii, A. nosocomialis, and A. pitti, have emerged as clinically significant in nosocomial infections and antibiotic resistance $[1,2]$. A. baumannii and $A$. nosocomialis are common causative agents of pneumonia in hospitals and constitute a large proportion of Acinetobacter-species pneumonia patients [3]. Although an $A$. baumannii infection has a higher mortality rate than $A$. nosocomialis, $A$. nosocomialis has recently been reported as increasingly being involved in clinical outbreaks and nosocomial infections [3,4]. However, the specific virulence factors of this microorganism have not been well-characterized.

Quorum sensing (QS) is a communication mechanism that bacteria use to monitor their cell density in order to regulate biofilm formation, virulence factor expression, and survival under stress conditions in different environments [5]. The QS of Gram-negative bacteria is regulated by the LuxI/LuxR regulatory system, which produces $N$-acyl-homoserine lactone (AHL) [6,7]. The Las and Rhl systems of $P$. aeruginosa and the AbaI/R system of A. baumannii belong to the LuxR/I family [5,6]. In Acinetobacter species, AbaI synthesizes $N$ acyl-homoserine lactone as autoinducer synthases and AbaR regulates the AHL synthesis of AbaI through an AbaR-AHL complex formation that binds to specific promoter sequences 
as autoinducer receptors (lux-box) [5,8]. Although Acinetobacter species generate various acyl chain lengths of QS signal molecules, A. baumannii and A. nosocomialis generate prime $\mathrm{N}$-(3-hydroxy dodecanoyl)-L-homoserine lactone (OH-dDHL) [8-10]. Studies have reported that AHL of the lengths $\mathrm{C} 14$ and $\mathrm{C} 16$ has been detected in Acinetobacter clinical strains; however, production differences may occur depending on the growth conditions in the laboratory $[8,11]$.

Various pathogens induce host cell death through virulence factors to evade immune responses and to survive [12,13]. Virulence factors of A. baumannii are well-known and include the outer membrane components, capsule, lipopolysaccharides, phospholipases, metal acquisition systems, and protein secretion systems [14,15]. In particular, the outer membrane protein A and outer membrane vesicles of both A. baumannii and A. nosocomialis have been reported to induce apoptosis of host cells [16-18]. Caspase activation in apoptosis plays a central role in cell death, differentiation, proliferation, and the intrinsic and extrinsic pathways and is involved in morphological features such as DNA fragmentation, cell contraction, and membrane blebbing [19]. In the intrinsic pathway, mitochondrial membrane potential $(\Delta \Psi \mathrm{m})$ and the release of cytochrome $\mathrm{c}$ from mitochondria also have important roles in the apoptosis mechanism $[19,20]$. In addition, reactive oxygen species (ROS) are related to the collapse of the mitochondrial membrane potential $(\Delta \Psi \mathrm{m})$ and the release of cytochrome $\mathrm{c}$, which activates caspase-9 and -3 sequentially [21]. The endoplasmic reticulum (ER) functions as an intracellular calcium storage, promotes cell survival and cell maintenance, and is involved in triggering apoptosis under stress conditions [22]. Calcium ions $\left(\mathrm{Ca}^{2+}\right)$ and caspase- 12 triggered by ER stress are involved in apoptosis mechanisms mediated through caspase- 9 and the release of cytochrome $\mathrm{c}$ from mitochondria [23].

Previous reports revealed that the QS molecule N-oxo-dodecanoyl-L-homoserine lactone, which contributes to the pathogenicity of P. aeruginosa, induces the intrinsic apoptosis of lymphocyte, macrophage, and epithelial cells, whereas $\mathrm{N}$-butanoyl-l-homoserine lactone does not $[24,25]$. Caspase-mediated apoptosis in response to the $\mathrm{OH}-\mathrm{dDHL}$ released by Acinetobacter species is not clearly established. Although the abaI mutant strain of A. baumannii reported decreased biofilm formation and motility [26], the in vivo colonization and dissemination of the $A$. nosocomialis anoI-deletion mutant strain remains to be identified. In this study, we investigated the induction of an ER-mediated apoptosis pathway with caspase- 12 and $\mathrm{Ca}^{2+}$ release and a mitochondrial-mediated pathway by $\mathrm{OH}-\mathrm{dDHL}$ in macrophages. In addition, the virulence of the anoI-deletion mutant strain in vivo was examined. We demonstrated that $\mathrm{OH}-\mathrm{dDHL}$ triggers apoptosis via the ER- and mitochondria-mediated pathways and through oxidative stress in bone marrowderived macrophages (BMDM), and that the anoI-deletion mutant strain decreased the pathogenicity compared to the $A$. nosocomialis wild-type strain.

\section{Results}

\subsection{Effect of AHLs on Cell Viability of Host Cells}

In previous reports, many Acinetobacter species showed different AHL profiles, and none of the AHL signals could be specifically assigned to species of the genus Acinetobacter [11]. We selected three types of AHL that are representative of the Acinetobacter species and investigated the cell viability of the host cells depending on the type of AHL $[10,11]$. Both N-hexanoyl-DL-homoserine lactone (C6-HSL: HHL) and N-decanoyl-DL-homoserine lactone (C10-HSL: DHL) slightly impacted cell viability in the primary cell, monocyte, and epithelial cell lines (Figure 1). However, OH-dDHL decreased the viability of the host cells by $>70 \%$ (Figure 1). In addition, cell viability with $\mathrm{OH}-\mathrm{dDHL}$ decreased in a time- and dose-dependent manner for BMDM (Figure $2 a, b$ ) and the same results were shown for A549 cells, HEp-2 cells, and THP-1 cells (Figure S1). To further determine the potential role of $\mathrm{OH}-\mathrm{dDHL}$ in regulating the viability of host cells, we treated BMDM cells with $\mathrm{OH}-\mathrm{dDHL}$ at different time points and then analyzed the typical morphological features through DAPI staining, DNA fragmentation analysis, and Annexin V/PI double staining. 
Cell death, such as DNA fragmentation, cellular shrinkage, round-up, and detachment from the culture plate and nuclear condensation were clearly identified by morphological analysis after $6 \mathrm{~h}$ by $50 \mu \mathrm{M}$ of OH-dDHL (Figure 2c,d). Furthermore, OH-dDHL showed significantly increased effects on the death of cells that were treated with OH-dDHL in a dose-dependent manner (Figure 2e). These results revealed that $\mathrm{OH}-\mathrm{dDHL}$ induces the apoptosis of host cells in a dose- and time-dependent manner.
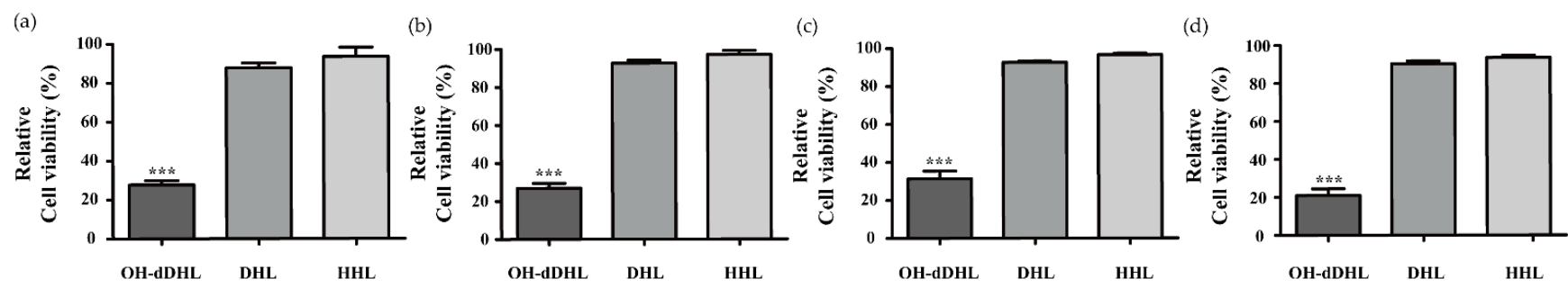

Figure 1. Effect of C6-HSL (HHL), C10-HSL (DHL), and OH-dDHL on the cell viability of host cells. (a) BMDMs were treated with $50 \mu \mathrm{M}$ AHLs for $24 \mathrm{~h}$. (b) THP-1 cells, (c) A549 cells, and (d) HEp-2 cells were treated with $100 \mu \mathrm{M}$ AHLs for $24 \mathrm{~h}$ and cell viability was measured with the CCK assay. Data are presented as mean \pm SEM of three independent experiments. ${ }^{* * *}, p<0.001$ vs. DHL and HHL.

(a)

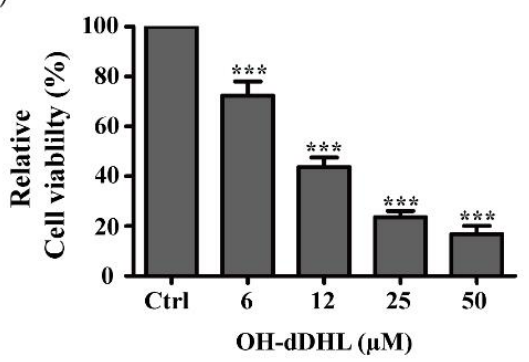

(b)

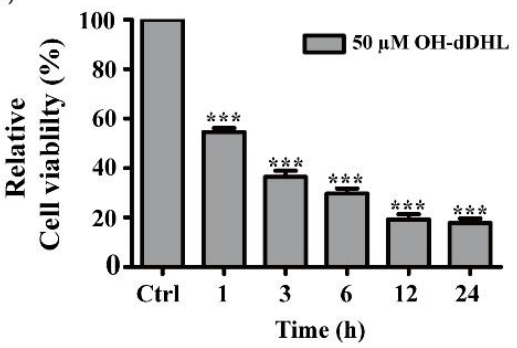

(c)

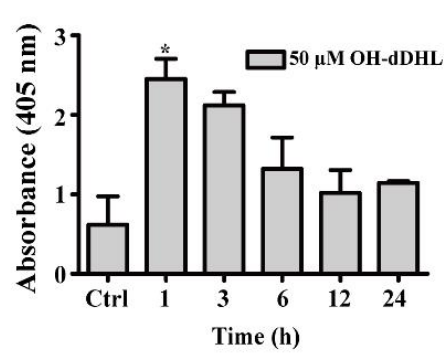

(d)
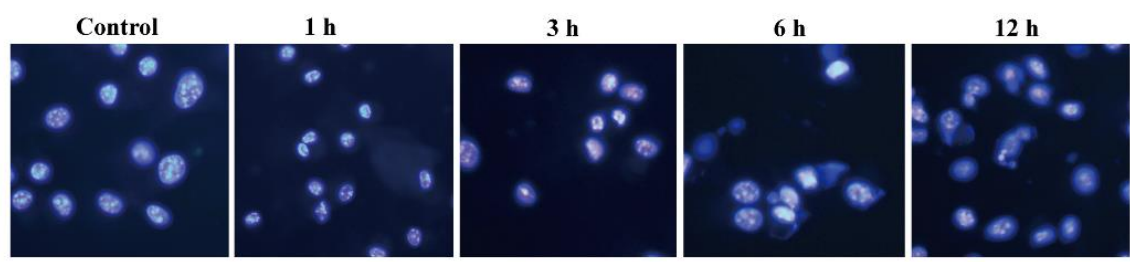

(e)

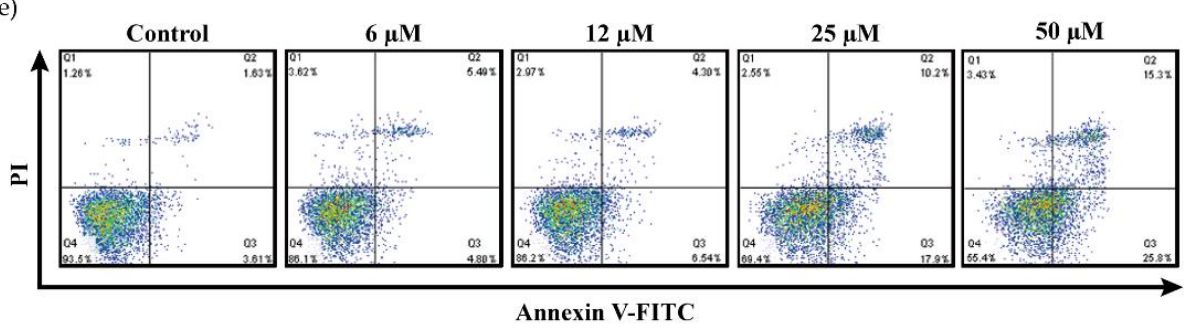

Figure 2. OH-dDHL-induced apoptosis in BMDMs. (a,b) Cell viability was determined using CCK assay. BMDMs were treated with $\mathrm{OH}-\mathrm{dDHL}$ in a time- and dose-dependent manner for $24 \mathrm{~h}$. (c) DNA fragmentation was analyzed using a Cell Death Detection ELISA kit in $50 \mu \mathrm{M}$ OH-dDHL-treated BMDMs in a time-dependent manner. Data are presented as mean \pm SEM of three independent experiments. ${ }^{* *}, p<0.001,{ }^{*}, p<0.05$ vs. control. (d) Apoptotic cells were stained with DAPI. Images were captured using a fluorescence microscope. Magnification: $\times 400$. (e) Apoptotic population was stained with Annexin V/PI and detected using Flow cytometry. 


\subsection{OH-dDHL Induced Cell Death by Caspase Activation}

AHL's ability to trigger cell-death-related events when released by P. aeruginosa has been previously reported [27], but it is not known whether it is associated with apoptosis signaling by Acinetobacter species. Since the induction of apoptosis is the most well-known caspase-dependent activation of programmed cell death [19], we investigated whether $\mathrm{OH}-\mathrm{dDHL}$-induced apoptosis occurs due to caspase-activation cascades in BMDM cells. For this purpose, we performed time-course experiments of the caspase cascade for up to $24 \mathrm{~h}$ at $50 \mu \mathrm{M}$ of OH-DHL. The increases in the cleaved forms of caspase-8, -9 , and -3 and PARP were most pronounced within $1 \mathrm{~h}$ by $\mathrm{OH}-\mathrm{dDHL}$ on BMDMs and remained elevated for up to $24 \mathrm{~h}$ (Figure 3a). We also analyzed the caspase-activity of A549 cells by adding $100 \mu \mathrm{M} \mathrm{OH}-\mathrm{dDHL}$ and cleaved caspase-8, -9 , and -3 were increased as shown in Figure S2.
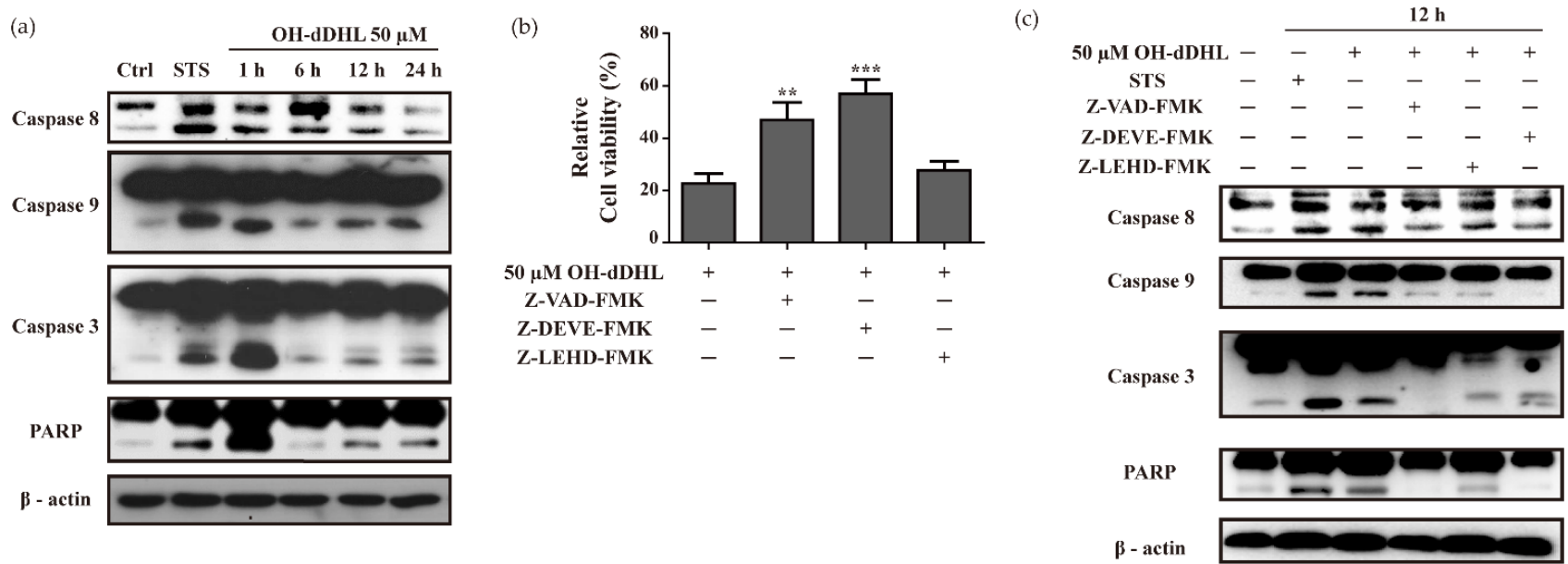

Figure 3. OH-dDHL-induced caspase activation. (a) BMDMs were treated in a time-dependent manner. Staurosporine (STS) was used as a positive control. Caspase- $8,-9$, and -3 , and PARP were analyzed using Western blot. Ctrl; negative control. (b) Caspase inhibitor $30 \mu \mathrm{M}$ Z-VAD-FMK, $40 \mu \mathrm{M}$ Z-DEVE-FMK, $30 \mu \mathrm{M}$ Z-LEHD-FMK pretreated BMDMs were treated with $50 \mu \mathrm{M} \mathrm{OH}-\mathrm{dDHL}$ and cell viability was measured with CCK assay. Data are presented as means \pm SEM of three independent experiments. ${ }^{* * *}, p<0.001,{ }^{* *}, p<0.01$ vs. OH-dDHL. (c) Western blot of caspase- $8,-9$, and -3 , and PARP in caspase inhibitor-pretreated BMDMs with $50 \mu \mathrm{M}$ OH-dDHL.

To further determine whether OH-dDHL-induced apoptosis was inhibited by caspase inhibitors such as Z-VAD-FMK (pan-caspase inhibitor), Z-DEVE-FMK (caspase-3 inhibitor), and Z-LEHD-FMK (caspase-9 inhibitor), these were applied to the cells for $1 \mathrm{~h}$ before $\mathrm{OH}-\mathrm{dDHL}$ treatment. Pan-caspase inhibitor and caspase- 3 inhibitor restrained apoptosis $>15 \%$ with OH-dDHL, but caspase-9 inhibitor showed no significant inhibitory effect (Figure 3b). All the caspase inhibitors partially or completely inhibited caspase and PARP activation of the $\mathrm{OH}-\mathrm{dDHL}-$ treated cells (Figure 3c). These results demonstrate that $\mathrm{OH}-$ $\mathrm{dDHL}$ induced the caspase activating cascade by intrinsic and extrinsic pathways and suggest that $\mathrm{OH}-\mathrm{dDHL}$ could cause mitochondria-dependent and -independent apoptosis in the BMDMs.

\subsection{OH-dDHL Induced ER Stress Response in BMDM}

The endoplasmic reticulum (ER) is the primary organ responsible for the proper folding and processing of early protein and $\mathrm{Ca}^{2+}$ homeostasis [22]. Disrupted ER function leads to a condition known as ER stress [22]. However, sustained and severe ER stresses lead to cell death via apoptosis [19]. To investigate whether OH-dDHL induces an ER stress response, we checked the production levels of the ER stress markers BIP, IRE1 $\alpha$, ATF6 $\alpha$ (p90, p50), p-eIF2 $\alpha$, CHOP, and caspase-12 in BMDMs over time via immunoblotting. $\mathrm{OH}-\mathrm{dDHL}$ treatment strongly induced the production of ER stress-sensor molecules in the UPR and ER, such as BIP, IRE1, ATF6, as well as the phosphorylation of eIF2 $\alpha$; these 
proteins' levels were increased after $1 \mathrm{~h}$ of $\mathrm{OH}-\mathrm{dDHL}$ treatment in BMDMs (Figure 4a). In particular, $\mathrm{CHOP}$ and caspase-12, which are associated with apoptosis, were remarkably activated. The production levels of CHOP were shown to be affected in BMDMs by OH$\mathrm{dDHL}$ in a time-dependent manner, with a maximal increase observed after a 1-h and 6-h incubation (Figure 4a). In addition, the levels of pro-caspase-12 were not significantly altered but the level of the active form caspase-12 was slightly increased until $12 \mathrm{~h}$ of $\mathrm{OH}-\mathrm{dDHL}$ treatment, returning to early time values at $24 \mathrm{~h}$. The cleaved caspase- $9,-3$, and PARP were correlated with this result, as observed in OH-dDHL-treated cells after a 1-h incubation (Figure 3a). These results indicated that the activation of $\mathrm{CHOP}$ under $\mathrm{OH}-$ dDHL induced ER stress conditions and decreased the mitochondrial membrane potential, leading to cytochrome c release. The OH-dDHL-induced ER stress led to cell death in BMDMs mediated by caspase-12 activation (mitochondria-independent pathway) but also through the mitochondria-dependent pathway that relies on cytochrome c release and the subsequent activation of caspase- 9 and -3 , leading to the cleavage of apoptosis substrates.

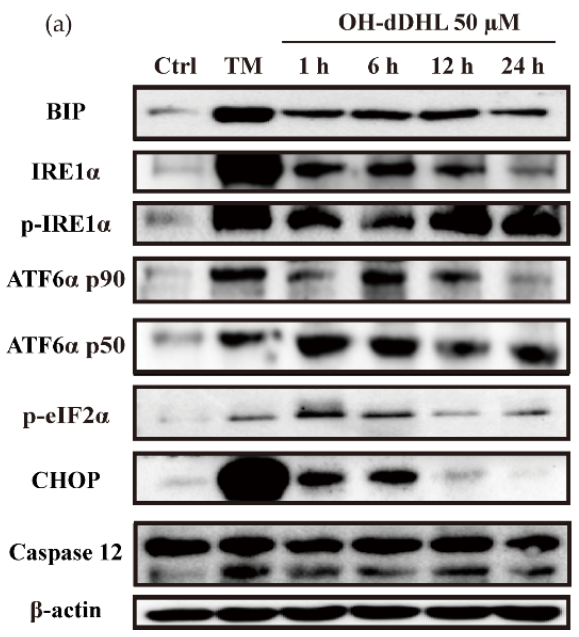

(b)

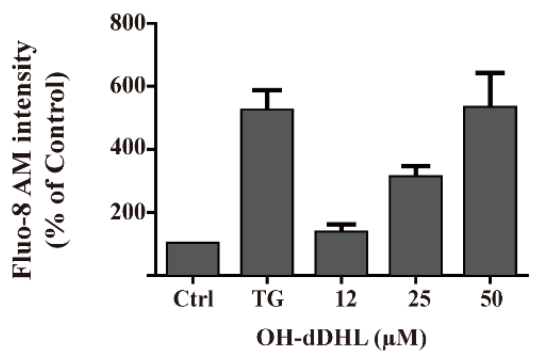

(c)

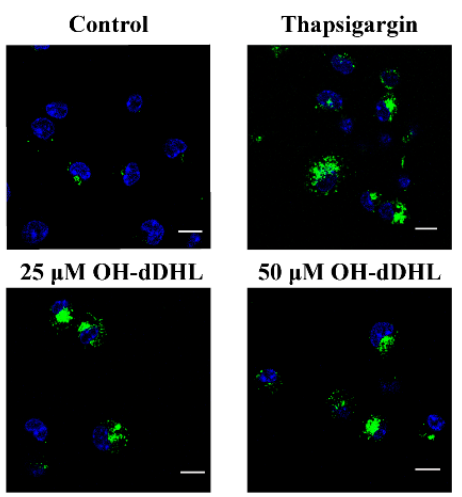

Figure 4. OH-dDHL-induced apoptosis through ER stress. (a) BMDMs were treated with $50 \mu \mathrm{M}$ OH-dDHL in a timedependent manner. All signal molecules were analyzed using Western blot. Tunicamycin (TM) was used as a positive control. Ctrl; negative control. (b) BMDMs were stained with Fluo-8 AM for $1 \mathrm{~h}$ and treated with OH-dDHL in a dose-dependent manner. The fluorescence signals were measured at $E m=520 \mathrm{~nm}$. Thapsigargin (TG) was used as a positive control. Data are presented as mean \pm SEM of three independent experiments. (c) BMDMs with OH-dDHL for $1 \mathrm{~h}$ were incubated with Fluo-8 AM in HBSS (Hanks' Balanced Salt Solution) at $37^{\circ} \mathrm{C}, 5 \% \mathrm{CO}_{2}$ incubator for $1 \mathrm{~h}$ and were imaged with a confocal microscope using the FITC channel. Scale bar, $10 \mu \mathrm{m}$.

Next, we investigated whether the cytoplasmic free calcium concentration is affected by OH-dDHL. The cells were stained using Fluo- 8 AM. As shown in Figure $4 b, c$, the calcium concentration of the cells was significantly higher than that in the control and overloaded calcium was determined using a confocal microscope, suggesting that $\mathrm{OH}-\mathrm{dDHL}$ could induce cytoplasmic calcium overload and, thus, induce cell damage. These results suggest that OH-dDHL induces cytoplasmic free calcium through the depletion of the ER calcium store and the activation of the unfolded protein response.

\subsection{OH-dDHL Induced ROS Production and Mitochondrial Dysfunction in BMDM}

The balance of intracellular ROS is tightly regulated by physiologic conditions; disrupting this balance can lead to excessive ROS production, oxidative damage including ER and mitochondria, and apoptosis [21]. We utilized CM- $\mathrm{H}_{2} \mathrm{DCFDA}$ and $\mathrm{DiOC}_{6}$, which are fluorogenic dyes, to determine the effects of OH-dDHL on cellular ROS production and mitochondrial membrane potential. As shown in Figure 5a, ROS generation by OH-dDHL resulted in a noticeable increase in fluorescence intensity after $1 \mathrm{~h}$ and the STS positive control and $\mathrm{H}_{2} \mathrm{O}_{2}$ increased it to a similar degree. The OH-dDHL-induced ROS generation 
was significantly reduced by the pre-treatment with NAC (ROS scavenger). The mitochondrial membrane potential was also analyzed and there was a slight decrease after the $\mathrm{OH}-\mathrm{dDHL}$ treatment relative to the control, confirming the reduction in mitochondrial membrane potential using confocal microscopic analysis (Figure $5 b, c$ ). In addition, the release of cytochrome $\mathrm{c}$ from the mitochondria and their subsequent translocation to the cytosol were evaluated using the immunoblots of the mitochondrial- and cytosolic-fraction obtained from the OH-dDHL-treated BMDMs for $1 \mathrm{~h}, 6 \mathrm{~h}$, and $12 \mathrm{~h}$. It was observed that the cytochrome c levels in the cytosol were gradually increased up to $12 \mathrm{~h}$ after the $\mathrm{OH}$ $\mathrm{dDHL}$ treatment (Figure 5d). These results support that OH-dDHL-induced cellular ROS and mitochondria dysfunction also activate apoptosis as an intrinsic signaling pathway associated with ER stress.

(a)

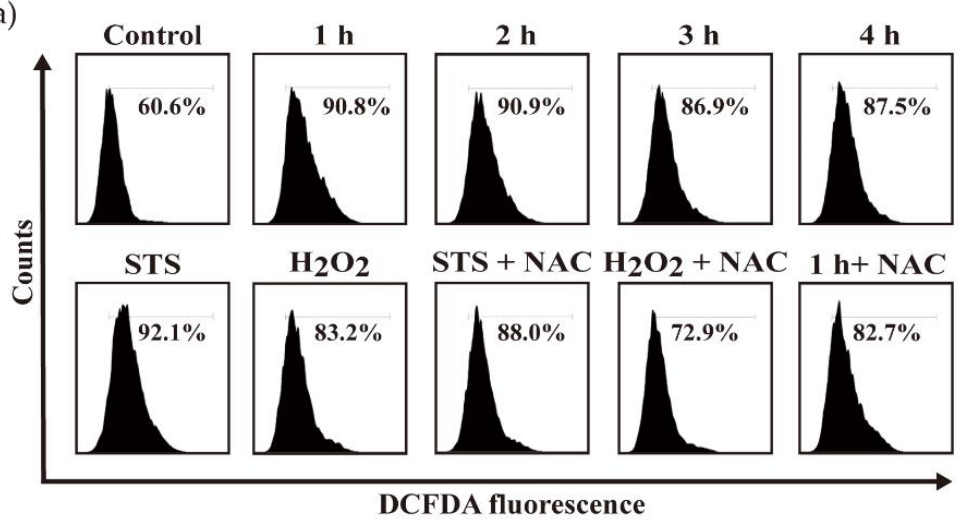

(c)

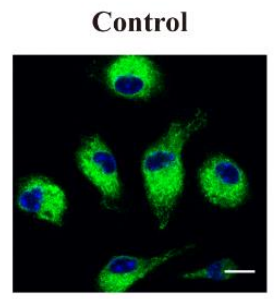

$6 \mathrm{~h}$

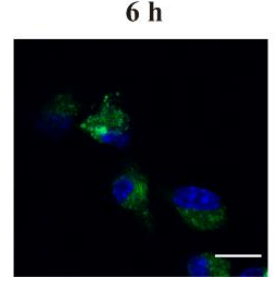

$1 \mathrm{~h}$

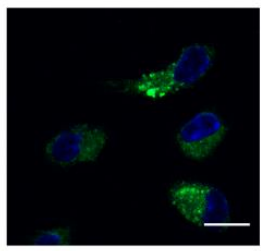

$9 \mathrm{~h}$

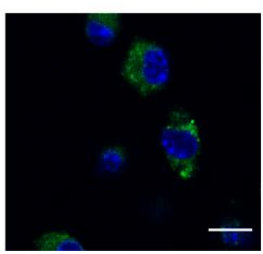

(b)

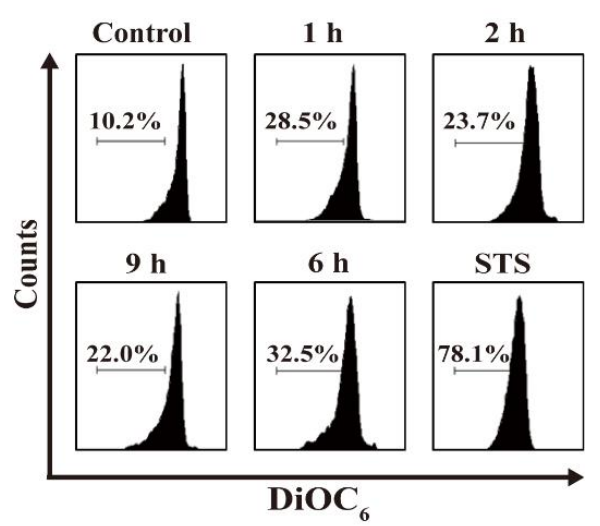

(d)

Figure 5. OH-dDHL induced ROS production and mitochondrial dysfunction in BMDMs. (a) BMDMs were treated with $50 \mu \mathrm{M} \mathrm{OH}-d D H L$ in a time-dependent manner; STS $(500 \mathrm{nM})$ and $\mathrm{H}_{2} \mathrm{O}_{2}(850 \mu \mathrm{M})$ for 4 h were used as positive controls; NAC (10 mM) stained with CM- $\mathrm{H}_{2}$ DCFDA for ROS analysis followed by flow cytometry. (b) BMDMs were treated with $50 \mu \mathrm{M} \mathrm{OH} \mathrm{dDHL}$ and stained with 3,3'-dihexyloxacarbocyanine iodide $\mathrm{DiOC}_{6}$. Cells were analyzed using flow cytometry. (c) BMDMs were treated with $50 \mu \mathrm{M} \mathrm{OH}-\mathrm{dDHL}$ and imaged with a confocal microscope using the FITC channel. Scale bar, $10 \mu \mathrm{m}$. (d) BMDMs were treated with $50 \mu \mathrm{M}$ OH-dDHL in a time-dependent manner. Cytochrome c analyzed using Western blot in cytosol fraction and mitochondria fraction. UT; negative control.

\subsection{Effect of Lipid Raft and PON2 on Cell Viability of BMDMs}

Cholesterol in the plasma membrane, which acts as a receptor for AHL and paraoxonase-2 (PON 2), catalyzes the hydrolysis of AHL. Both of these mechanisms have been implicated in promoting AHL-induced cell death $[28,29]$. To investigate the functional significance of plasma-membrane cholesterol and the functional relevance of PON2 hydrolase to mediate 
the cellular damage caused by $\mathrm{OH}-\mathrm{dDHL}$ in BMDM, the lipid raft inhibitor methyl- $\beta$ cyclodextrin $(\mathrm{M} \beta \mathrm{CD})$ and PON2 inhibitor $((1,2,4)$ triazolo $(4,3-\mathrm{a})$ quinolone; (TQ416)) was used to deplete cholesterol and inhibit PON2 activity. The PON2 expression level in BMDMs with $50 \mu \mathrm{M}$ OH-dDHL was markedly increased compared to those in the controls (Figure 6a). TQ416 inhibited the effects of cytotoxicity by OH-dDHL by $>15 \%$ in BMDMs, whereas pre-treatment with M $\beta C D$ did not affect the BMDMs. (Figure 6b). In the A549 cells, TQ416 significantly inhibited the cytotoxicity of OH-dDHL and M $\beta C D$ inhibited it by $>9 \%$ (Figure S3). Thus, the data demonstrate that the hydrolysis of PON2 induced OH-dDHL cytotoxicity and the fluidity of the cell membrane to lipophilic OH-dDHL permeability varies depending on the cell characteristics.

(a)

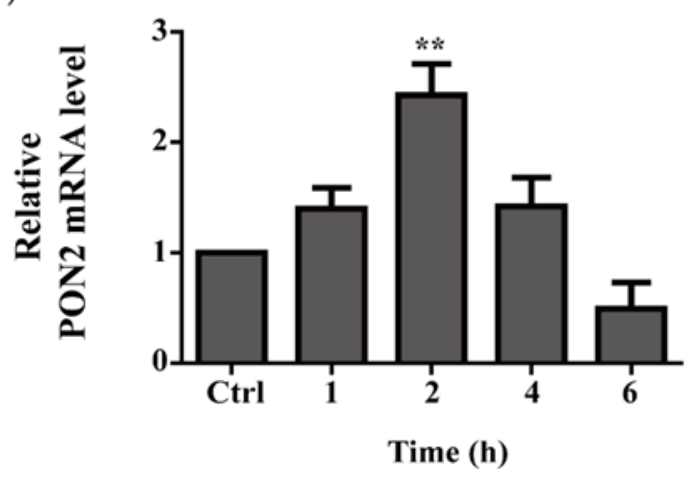

(b)

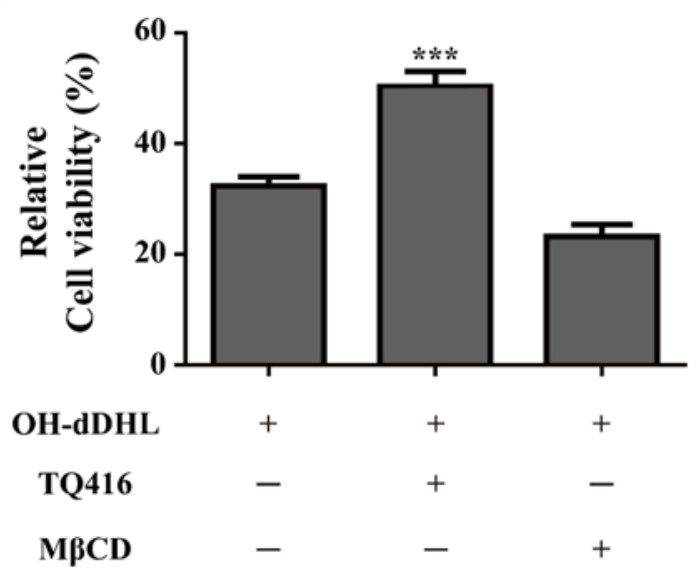

Figure 6. Effect of lipid raft and PON2 on BMDM cells treated with OH-dDHL. (a) BMDMs were treated with $50 \mu \mathrm{M}$ $\mathrm{OH}-\mathrm{dDHL}$ in a time-dependent manner. Relative expression of mRNA was measured using a real-time quantitative PCR. Gene expression was normalized with GAPDH. (b) Cell viability was determined using CCK assays. M $\beta C D(2 \mu M)$ was pre-applied for $1 \mathrm{~h}$ and TQ416 $(4 \mu \mathrm{M})$ was applied simultaneously. BMDMs were treated with $50 \mu \mathrm{M}$ OH-dDHL for $3 \mathrm{~h}$. Data are presented as mean \pm SEM of three independent experiments. ${ }^{* * *}, p<0.001,{ }^{* *}, p<0.01$ vs. OH-dDHL.

\subsection{Pro-Inflammatory Cytokine Gene Expression Is up Regulated by OH-dDHL on BMDMs}

Although several studies have suggested that AHL enhances the pro-inflammatory response, other studies have indicated that AHL provides anti-inflammatory effects, thus contributing to the establishment of a persistent infection [25,30]. To determine the effect of $\mathrm{OH}-\mathrm{dDHL}$ on inflammatory signaling in BMDM, we confirmed the qPCR amplification efficiency of each primer and stable reference gene Cq values (Figure S4), and then measured the transcription of pro-inflammatory genes using a real-time quantitative PCR. The BMDMs were treated for $6 \mathrm{~h}$ in the presence or absence of OH-dDHL, the results of which are summarized in Figure 7. The TNF- $\alpha$, IL-1 $\beta$, IL-6, IL-8, and MCP-1 expression levels were markedly increased up to twofold compared to those in the control at an incubation time of $2 \mathrm{~h}$, but then decreased to the level of the untreated control. These results indicate that $\mathrm{OH}-\mathrm{dDHL}$ mediates the initial inflammatory response. 

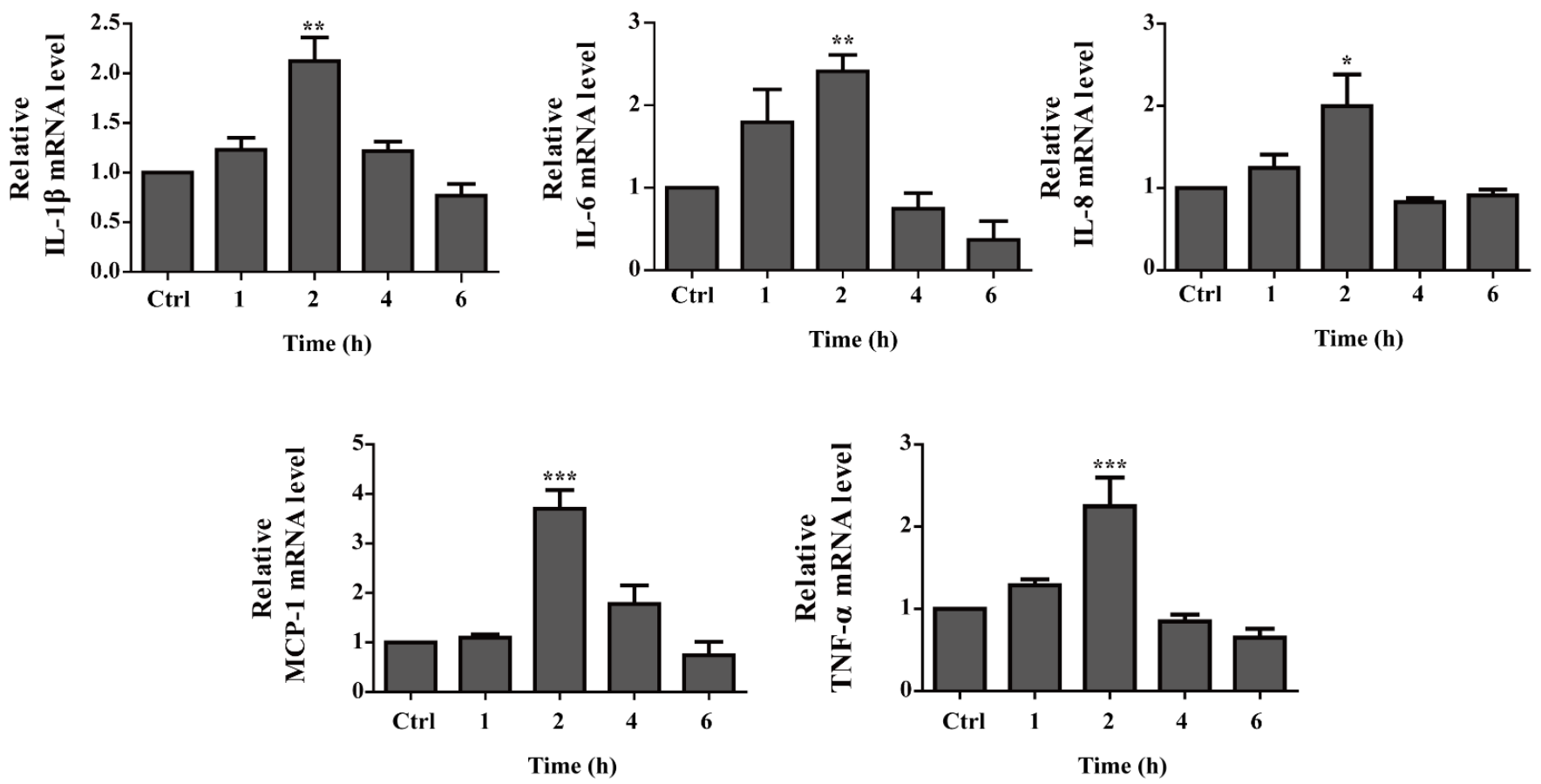

Figure 7. $\mathrm{OH}-\mathrm{dDHL}$-induced pro-inflammatory cytokine expression in BMDMs. BMDMs were treated with $50 \mu \mathrm{M} \mathrm{OH}-$ $\mathrm{dDHL}$ in a time-dependent manner. The relative expression of mRNA was measured using a real-time quantitative PCR. Gene expression was normalized with GAPDH. Data are presented as mean \pm SEM of three independent experiments. ${ }^{* * *}, p<0.001{ }^{* *}, p<0.01 .^{*}, p<0.05$ vs. control.

\subsection{Lung Colonization and Virulence by A. nosocomialis}

To further characterize the virulence of $A$. nosocomialis, we evaluated the intracellular bacteria number in infected BMDMs with wild-type and the anoI-deletion mutant. The intracellular bacteria number of the wild-type strain was significantly higher than that of the anoI-deletion mutant strain (Figure 8a). In addition, the intracellular anoI-deletion mutant strain was significantly decreased in A549 cells (Figure S5). In intratracheally infected BALB/c mice in the pneumonia model, the survival rate was observed for six days after infection. The wild-type strain showed a $50 \%$ survival rate after three days and $0 \%$ after five days. However, the mutant strain showed a $40 \%$ survival rate after six days (Figure 8b). The mice were sacrificed three days post-infection to observe their histopathological features. The anoI-deletion mutant strains showed significantly reduced histopathological features in which lymphocytes and macrophages had been recruited in the alveolar spaces. In addition, the pathological inflammation of the mice infected with the mutant strain was reduced compared to the wild-type strain.

We stained with anti-rabbit polyclonal OmpA for A. nosocomialis detection. The wildtype strains were found to have significantly more bacterial aggregates around the bronchus and the bronchoalveolar epithelium than the anoI-deletion mutant strains (Figure 8c). The anoI-deletion mutant strain showed decreased CFUs compared to the wild-type strain in the lung, and the dissemination from the lungs to the kidney had also declined (Figure $8 \mathrm{~d}-\mathrm{f}$ ). Our results show that $\mathrm{OH}-\mathrm{dDHL}$ production plays an important role in pathogenicity, such as the colonization of $A$. nosocomialis in the early stages of cell invasion and infection. 
(a)

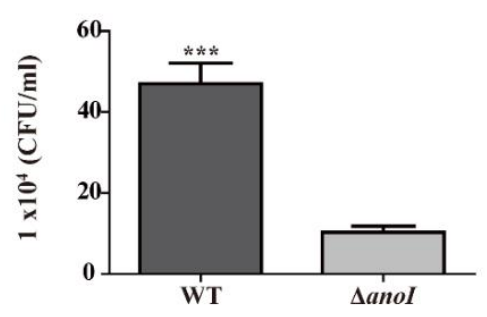

(c)

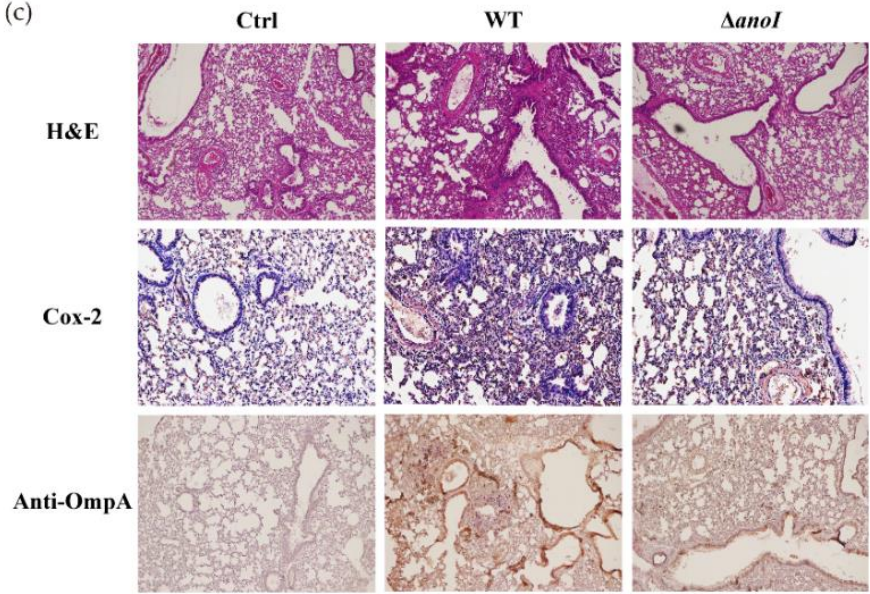

(b)

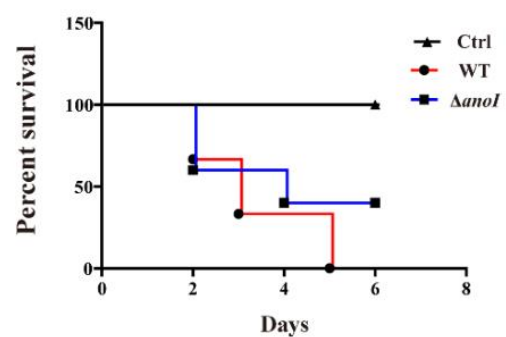

(d)

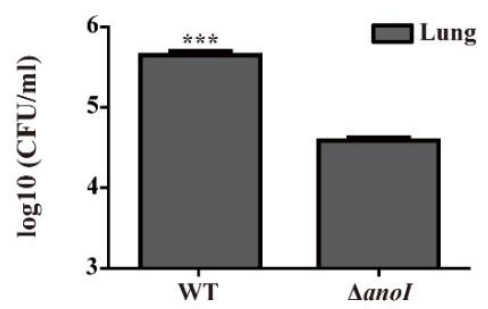

(e)
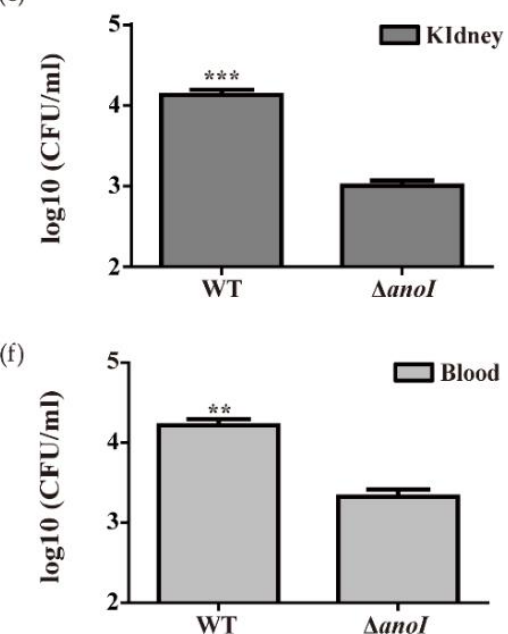

Figure 8. Lung colonization and virulence by A. nosocomialis. (a) BMDMs were infected with WT, $\Delta a n o I$, at an MOI of 100 for $6 \mathrm{~h}$ and incubated for $2 \mathrm{~h}$ in complete medium containing gentamicin, followed by additional incubation in complete medium for 16 h. $\triangle a n o I$. Data are presented as mean \pm SEM of three independent experiments. (b) Survival curve of neutropenic BALB/c mice infected with A. nosocomialis. Neutropenic BALB/c mice were intratracheally infected with WT, $\triangle a n o I$, and their survival rate was monitored twice a day. (c) Histological analysis of lungs in the mice three days post-infection. Representative histopathological sections of hematoxylin and eosin-stained lungs from neutropenic BALB/c mice infected with $A$. nosocomialis. Anti-OmpA antibody labeled lung sections WT, $\Delta a n o I$. The lungs of mice infected with WT and $\Delta a n o I$ showed areas of inflammatory cell infiltration. Magnification: $\times 100$. $(\mathbf{d}-\mathbf{f})$ Mice were intratracheally infected with $A$. nosocomialis strains and the number of bacteria in the lungs, blood, and kidneys three days post-infection was determined. Statistical significance was checked using Student's $t$-test. ${ }^{* *}, p<0.001,{ }^{* *}, p<0.01$ compared with $\Delta$ anoI.

\section{Discussion}

Pathogenic bacteria have important interactions with immune cells at the site of infection and have evolved to survive and replicate by subverting immune responses [31]. The innate immune response mainly consists of the protective abilities of neutrophils and macrophages [15]. In an Acinetobacter infection, monocytes and macrophages are activated in an early stage of infection; in particular, alveolar macrophages in early infections react first at the site of infection before recruiting neutrophils [32,33]. While the innate immune response plays an important role in inducing apoptosis to eliminate the bacteria, the bacteria control apoptosis using various factors, including toxins and virulence factors, for invasion into the bloodstream or dissemination into other organs [34,35]. For example, Staphylococcal pore-forming toxins (PFTs), E. coli outer membrane vesicles (OMVs), Shigella toxin, P. aeruginosa toxin, and QS molecules induce macrophage death $[36,37]$. In this study, we have demonstrated that the $\mathrm{OH}-\mathrm{dDHL}$ of $A$. nosocomialis induces ER- and mitochondriamediated apoptosis of BMDMs.

Short acyl chain QS molecules, including N-butanoyl-1-homoserine lactone (BHL), $\mathrm{N}$-(3-oxo-hexanoyl)-L-homoserine lactone (OHHL), $N$-hexanoyl-DL-homoserine lactone (C6-HSL: HHL), and N-decanoyl-DL-homoserine lactone (C10-HSL: DHL) showed no cytotoxicity effect on the host cells [24]. We confirmed that DHL, HHL, and OH-dDHL 
produced by Acinetobacter spp. are cytotoxic. Exclusively, $\mathrm{OH}-\mathrm{dDHL}$ decreased the cell viability of THP-1, HEp-2, A549, and BMDMs (Figure 1). At a concentration of $50 \mu \mathrm{M}$ or more, cell viability decreased in a time-dependent fashion (Figure 2 and Figure S1). In addition, we demonstrated that $\mathrm{OH}-\mathrm{dDHL}$ induced apoptosis through a caspase-dependent pathway (Figure 3). These results are consistent with a previous report that 3-oxo-C12-HSL induces the apoptosis of immune cells and human colon cancer cell lines [30,38].

In ER stress, the ER stress markers IRE1, ATF6, and PERK are activated by unfolded protein accumulation, which activates molecules such as downstream p-eIF $2 \alpha$ and CHOP, which are major markers of the ER stress-mediated mitochondrial pathway of apoptosis involving oxidative stress and an impaired mitochondrial function [22]. The $\mathrm{Ca}^{2+}$ released from the ER triggered by an ER stressor is directly related to the mitochondria, activates caspase-12, and induces the ER stress-mediated mitochondrial pathway of apoptosis through oxidative stress and activated Bax and Bak [23]. However, caspase-12 directly activates caspase- 9 and -3 , independent of the mitochondrial pathway $[23,39]$. Although we could not detect the activation of phosphate PERK, we demonstrated the activation of p-eIF $2 \alpha$ by OH-dDHL. We observed ER stress with transmembrane protein (IRE1 and ATF6a p50) aggregation induced by $\mathrm{OH}-\mathrm{dDHL}$ in BMDMs and subsequent $\mathrm{CHOP}$ and caspase-12 activity. $\mathrm{Ca}^{2+}$ was released into the cytosol immediately in treated BMDMs (Figure 4). CHOP and caspase-12 were activated within $15 \mathrm{~min}$ in BMDMs by OH-dDHL (data not shown). Intrinsic pathway apoptosis is involved in mitochondria dysfunction such as increased outer mitochondrial membrane permeabilization [21,22]. The collapse of the mitochondrial membrane potential $(\Delta \Psi \mathrm{m})$ and the consequent activation of Bax and $\mathrm{Bak}$ by an ROS such as $\mathrm{H}_{2} \mathrm{O}_{2}$ results in cytochrome c release, leading to caspase- 9 and -3 activation [21]. It has been previously reported that 3-oxo-C12-HSL promotes the release of $\mathrm{Ca}^{2+}$ from the ER in nonpolarized airway epithelial cells and triggers apoptosis by the Bak/Bax-independent release of cytochrome $\mathrm{c}$ and both the extrinsic and intrinsic pathways $[27,40,41]$. Although the precise molecular mechanism of OH-dDHL action and the activation of Bax and Bak on mitochondria is undetermined, our study showed that $\mathrm{OH}-$ $\mathrm{dDHL}$ induces an apoptotic signaling pathway that activates caspase-9, and -3 by directly acting on mitochondria to release cytochrome $\mathrm{c}$ and ROS generation. Since the effect of ER stress on $\triangle \Psi \mathrm{m}$ occurs within an hour after $\mathrm{ER} \mathrm{Ca}^{2+}$ depletion, it is $\mathrm{OH}$-dDHL-induced $\mathrm{ER} \mathrm{Ca}^{2+}$ release that will indirectly cause the depolarization of $\Delta \Psi \mathrm{m}$. Therefore, it appears that ER stress signaling is indirectly involved in the depolarization of OH-dDHL-mediated $\triangle \Psi \mathrm{m}$. Thus, these data indicate that OH-dDHL triggers apoptosis through both the ERand mitochondria-mediated pathways.

The lipophilic $N$-acyl-homoserine lactone can easily infiltrate into host cells [30]. Lipid rafts are involved in cell signaling, LPS signaling in macrophages, and pathogen phagocytosis $[30,42]$. It was previously reported that the epithelial barrier dysfunction by 3oxo-C12-HSL is associated with lipid rafts and the lipid rafts inhibitor, $M \beta C D$, inhibited the loss of the TJ protein and the permeability of the Caco-2 monomer by 3-oxo-C12-HSL [29]. However, $\mathrm{M} \beta C D$ has a minor effect on LS174T cells [30]. PON2 with lactonase activity has reportedly induced ER stress and Bak/Bax-independent apoptosis by a hydrolyzed 3-oxo-C12-HSL-acid accumulation in cells [43]. TQ416 inhibits PON2 activity and the cytotoxicity of 3-oxo-C12-HSL on LS174T cells [30]. As shown in Figure 6 and Figure S3, TQ416 inhibits the cytotoxicity of OH-dDHL on BMDMs and A549 cells. M $\beta C D$ inhibited the cytotoxicity of OH-dDHL on A549 cells and had no effect on BMDMs. Considering the increased cell viability when PON2 activity was inhibited by TQ416, it is thought that $\mathrm{OH}-\mathrm{dDHL}$ directly induces caspase- 8 activity, mitochondrial dysfunctions, and ROS generation. This denotes that studies are needed on the upstream stress response other than $\mathrm{OH}-\mathrm{dDHL}$ acidification. Our results indicated that OH-dDHL cytotoxicity by lipid raft suppression occurs due to differences in the characteristics of epithelial cells and phagocytic cells, and OH-dDHL acid accumulation by PON2 induces a cellular response consistent with hydrolyzed 3-oxo-C12-HSL acid accumulation. 
In our study, we have demonstrated that $\mathrm{OH}-\mathrm{dDHL}$ modulates the pro-inflammation cytokines MCP-1, IL-8, TNF- $\alpha$, IL-1 $\beta$, and IL-6 (Figure 7) and we have shown that caspase-8 is activated by $\mathrm{OH}-\mathrm{dDHL}$ (Figure 3 ). The extrinsic apoptosis pathway is mediated through caspase- 8 by TNF and TRAIL [21]. The OMVs of $A$. baumannii and $A$. nosocomialis trigger pro-inflammatory cytokines, including IL-1 $\beta$, IL-6, MIP-1a, and MCP-1 [44]. Macrophage cells infected with $A$. baumannii reportedly secrete the inflammatory cytokines MIP-2, IL-6, and TNF- $\alpha$ [32]. Furthermore, infected mice have increased pro-inflammation cytokines IL-1 $\beta$, IL-6, MIP-2, and TNF- $\alpha$ [33]. The application of 3-oxo-C12-HSL to LS174T cells reportedly induces the pro-inflammation cytokines IL-1 $\beta$ and IL-8 [30], which elicit TNF- $\alpha$ in resting RAW264.7 [25]. In contrast, 3-oxo-C12-HSL suppresses the pro-inflammation cytokine TNF- $\alpha$ and increases the anti-inflammation cytokine IL-10 in stimulated RAW 264.7 [25]. We suggest that the inflammatory cytokines released by OH-dDHL are involved in the early stages of Acinetobacter infection, facilitating interference with the host response and dispersal to other sites of replication.

As noted above, the QS system is involved in biofilm formation; in particular, biofilms are important in colonization and adherence for host cell infection in the early stages [45]. Mutations in the autoinducer synthase LuxI reduce biofilms, which has been demonstrated in H. alvei, A. baumannii, and P. fluorescens [6,46,47]. In well-studied P. aeruginosa, it has been reported that lasI mutant strains in vivo showed less bacteria pathogenicity than wild-type strains [48]. We demonstrated that the anoI-deletion mutant had a decreased invasion and adhesion (Figure 8 and Figure S5). The anoI-deletion mutant showed significantly less virulence and dissemination in mouse models and immune responses in the lungs were also reduced (Figure 8). Our results suggest that the activity of OH-dDHL may be an important factor for invasion and proliferation in the early stages of infection. Although the pathogenicity regulation of the A. nosocomialis QS system was confirmed in this study, the QS concentration of Acinetobacter spp. in vivo has not been demonstrated. A previous study in cystic fibrosis patient sputum reported QS molecules of P. aeruginosa 1-20 nM [25] were found at low concentrations in vivo. However, QS molecules of P. aeruginosa are observed at $600 \mu \mathrm{M}$ in biofilms [25,49]. Previous studies have suggested that exposure to high concentrations of QS molecules is required for an appropriate biofilm formation in the host [49]. Thus, we speculate that Acinetobacter spp. will enable similar events. However, the exact QS concentration of Acinetobacter spp. in biofilms and in vivo should be clearly investigated.

In summary, we demonstrated that $\mathrm{OH}-\mathrm{dDHL}$ induced ER- and mitochondria-mediated apoptosis and the anoI-deletion mutant had decreased virulence in vivo. Overall, our data may provide new insights into the mechanism of host cell apoptosis by the QS molecule $\mathrm{OH}-\mathrm{dDHL}$ and contribute to our understanding of the interactions between $A$. nosocomialis and host cells in the early stages of infection.

\section{Materials and Methods}

\subsection{The Bacterial Strains, Culture Conditions}

The A. nosocomialis ATCC 17903 type strain and anoI-deletion mutant strains were grown separately in Luria-Bertani (LB) broth containing $1.5 \%(\mathrm{wt} / \mathrm{vol})$ agar at $37^{\circ} \mathrm{C}$. The anoI-deletion mutant strain was constructed using the conjugation method $[9,50,51]$. All bacterial cells were delivered without antibiotics at a density of $1.0 \times 10^{8} \mathrm{cfu} \mathrm{mL}^{-1}$ for the infection

\subsection{Reagent and Antibody}

Synthetic $N$-hexanoyl-DL-homoserine lactone (C6-HSL), $N$-decanoyl-DL-homoserine lactone (C10-HSL), N-(3-hydroxy dodecanoyl)-DL-homoserine lactone (OH-dDHL), tunicamycin, thapsigargin, hydrogen peroxide $30 \%$ (wt/vol) $\left(\mathrm{H}_{2} \mathrm{O}_{2}\right)$, N-Acetyl-l-cysteine (NAC), and staurosporine were purchased from Sigma-Aldrich (St. Louis, MO, USA). Antibodies with anti-caspase- 3 , anti-caspase- 8 , anti-cytochrome $c$, anti-PARP, anti- $\beta$-actin, anti-caspase-9, anti-VDAC, anti-CHOP, anti- caspase-12, anti-p-eIF2 $\alpha$, anti-IRE1 $\alpha$, and 
anti-BIP were purchased from Cell Signaling Technology (Danvers, MA, USA). Anti-pIRE1 $\alpha$ was purchased from Thermo Fisher Scientific (Waltham, MA, USA). Anti-ATF $6 \alpha$, anti-COX-2, and methyl- $\beta$-cyclodextrin $(\mathrm{M} \beta C D)$ were purchased from Santa Cruz Biotechnology (Paso Robles, CA, USA). Horseradish peroxidase-conjugated goat anti-rabbit IgG and goat anti-mouse IgG were purchased from Abcam (Cambridge, MA, USA). The pancaspase inhibitor (Z-VAD-FMK), caspase-3 inhibitor (Z-DEVE-FMK), and caspase-9 inhibitor (Z-LEHD-FMK) were purchased from R\&D Systems (Minneapolis, MN, USA). The paraoxonase 2 (PON2) inhibitor $((1,2,4)$ trizolo(4,3-a)quinolones; TQ416) was purchased from Maybridge (Cornwall, UK).

\subsection{Cell Culture}

A549 cells (human alveolar epithelial cell line; ATCC CCL-185) and HEp-2 cells (human laryngeal epithelial cell; ATCC CCL23) were cultured in Dulbecco's Modified Eagle Medium (DMEM; Welgene, Daegu, Korea) supplemented with 10\% fetal bovine serum (FBS; Welgene, Daegu, Korea) and 1\% antibiotic-antimycotic solution (Welgene, Daegu, Korea) at $37{ }^{\circ} \mathrm{C}$ in $5 \% \mathrm{CO}_{2}$. THP- 1 cells from human monocytic cells were grown in RPMI 1640 medium (Welgene, Daegu, Korea) and supplemented with 10\% FBS, 1\% nonessential amino acid, and $1 \mathrm{mM}$ sodium pyruvate (Sigma-Aldrich, St. Louis, MO, USA), and $1 \%$ antibiotic-antimycotic solution at $37^{\circ} \mathrm{C}$ in $5 \% \mathrm{CO}_{2}$. Bone marrow-derived macrophages (BMDMs) were generated by flushing bone marrow cells from the femurs and tibias of 6-8-week-old female C57BL/ 6 mice, cultured for four days in DMEM, and supplemented with $10 \% \mathrm{FBS}, 1 \%$ antibiotic-antimycotic solution, and $25 \mathrm{ng} / \mathrm{mL}$ mouse macrophage colony-stimulating factor (M-CSF) (R\&D Systems, Minneapolis, MN, USA) at $37^{\circ} \mathrm{C}$ in $5 \% \mathrm{CO}_{2}$.

\subsection{Determination of Cell Viability}

The BMDMs' viability was determined using the Cell Counting Kit-8 (CCK-8; Dojindo Laboratories, Gaithersburg, MD, USA). Cells were sub-cultured into 96-well microplates at $80 \%$ confluency at $37^{\circ} \mathrm{C}$. The cells were treated with OH-dDHL in a time- and dosedependent manner and pretreated with $\mathrm{M} \beta \mathrm{CD}$ inhibitors prior to OH-dDHL treatment, while TQ416 inhibitors were applied simultaneously. The viability of the cells was measured at $450 \mathrm{~nm} 1 \mathrm{~h}$ after treatment with CCK-8. The data are expressed as the percentage of viable cells relative to the untreated control cells, which was calculated using the absorbance ratio.

\subsection{Apoptosis Analysis}

Apoptotic cells were assessed via staining with an Annexin V/Propidium iodide (PI) staining kit in accordance with the manufacturer's instructions (BD Biosciences, San Diego, CA, USA). In brief, the cells were harvested and incubated with FITC-conjugated Annexin $\mathrm{V}$ and PI in the dark for $15 \mathrm{~min}$. Analysis of the stained cells was performed on an FACS Canto II (Becton-Dickinson, San Jose, CA, USA) with FACS Diva and the results were analyzed using FlowJo software (Tree Star, Ashland, OR, USA).

\subsection{Immunofluorescence Microscopic Analysis}

BMDMs were seeded $\left(1 \times 10^{6}\right.$ cells $\left./ \mathrm{mL}\right)$ onto glass coverslips in 12 -well plates and treated with $\mathrm{OH}-\mathrm{dDHL}$ for the indicated times. Nuclear changes in the cells were analyzed by staining with $4^{\prime}, 6$-diaminido-2-phenylindole (DAPI). The BMDM cells were fixed with $4 \%$ paraformaldehyde and incubated with a Vectashield mounting medium containing DAPI (Vector Laboratories, Burlingame, CA, USA) overnight in the dark at $4{ }^{\circ} \mathrm{C}$. The stained cells were observed using an Olympus BX50 fluorescence microscope (Olympus Optical Co., Hamburg, Germany). 


\subsection{Measurement of DNA Fragmentation by Cell Death Detection ELISAplus Kit}

The measurement of DNA fragmentation was performed in accordance with the manufacturer's instructions for the Cell Death Detection ELISA ${ }^{\text {PLUS }}$ kit (Roche Applied Science, Mannheim, Germany). First, BMDM cells were seeded in 96-well flat-bottom culture plates. After the cells were treated with $\mathrm{OH}-\mathrm{dDHL}$ in a time-dependent manner, the supernatant was transferred to a 96-well microtiter plate, and the absorbance was measured using an ELISA plate reader (SpectroMAX, CA, USA) at $405 \mathrm{~nm}$. The ratio of DNA fragmentation was expressed as the enrichment of DNA fragments in the treated sample:the DNA fragments in the control.

\subsection{Western Blot Analysis}

Cells were washed with cold PBS and lysed with RIPA lysis buffer (150 mM NaCl, $1 \%$ Triton X-100, 0.1\% SDS, 1\% sodium deoxycholate, $50 \mathrm{mM}$ Tris-HCl pH 7.5, 2 mM EDTA) containing protease inhibitor cocktail (Halt ${ }^{\mathrm{TM}}$, Pierce, Rockford, IL, USA) and $1 \mathrm{mM}$ phenylmethylsulfonyl fluoride (PMSF) for $15 \mathrm{~min}$ on ice. The cell lysates were cleared by centrifugation and quantified using a Bradford assay (Bio-Rad, Hercules, CA, USA). An equal amount of each sample was separated by $8 \%$ or $15 \%$ SDS-PAGE, followed by an electrotransfer onto a PVDF membrane (EMD Millipore, Danvers, MA, USA). The blots were blocked in $0.05 \%$ Tween 20 containing $5 \%$ skim milk and incubated with primary antibodies. The proteins were visualized by incubation with appropriate horseradish peroxidase-conjugated secondary antibodies, followed by enhanced chemilluminescence (WesternBright ECL kit; Advanstar, San Jose, CA, USA) according to the manufacturer's instructions.

\subsection{Measurement of ROS Production}

The intracellular hydrogen peroxide levels were measured via staining with the oxidant-sensitive fluorescent probe CM- $\mathrm{H}_{2}$ DCFDA (5-(and-6)-chloromethyl-2' ${ }^{\prime} 7^{\prime}$ dichlorodihydrofluorescein diacetate, acetyl ester) (Molecular Probes, Eugene, OR, USA). The cells were incubated with $\mathrm{OH}-\mathrm{dDHL}$ and then stained with $\mathrm{CM}-\mathrm{H}_{2} \mathrm{DCFDA}$ for $30 \mathrm{~min}$ at $37^{\circ} \mathrm{C}$ in the dark. The stained cells were immediately analyzed using the FACS Canto II with FACS Diva, and the results were analyzed using FlowJo software.

\subsection{Measurement of Mitochondria Membrane Potential $(\Delta \Psi m)$ and Confocal Microscopic Analysis}

BMDMs were seeded onto glass coverslips in 12-well plates and treated with $\mathrm{OH}-$ dDHL. Afterward, the cells were fixed with $4 \%$ paraformaldehyde (PFA; Sigma-Aldrich, St. Louis, MO, USA) and incubated with 3,3'-dihexyloxacarbocyanine iodide $\left(\operatorname{DiOC}_{6}(3)\right.$; Molecular Probes) at $37^{\circ} \mathrm{C}$ for $15 \mathrm{~min}$ in the dark. The stained cells were visualized using a Leica DMi8 confocal microscope (Leica Microsystems Ltd., Wetzlar, Germany). The mitochondrial membrane potential was determined by flow cytometer analysis using $\mathrm{DiOC}_{6}(3)$ staining. The harvested cells were incubated for $15 \mathrm{~min}$ at $37^{\circ} \mathrm{C}$ and then analyzed with a NovoCyte Flow Cytometer (ACEA Biosciences, Inc., San Diego, CA, USA). The percentages of the cells with membrane depolarization were calculated using FlowJo software (Tree Star, Ashland, OR, USA).

\subsection{Mitochondria Fractionation}

BMDMs were treated with OH-dDHL. The adherent and detached cells were harvested, and the mitochondrial fraction was carried out by using a Mitochondrial Isolation Kit (Pierce, Rockford, IL, USA), according to the manufacturer's instructions.

\subsection{Measurement of Intracellular Calcium $\left(\mathrm{Ca}^{2+}\right)$}

A cell-permeable Fluo-8 AM (Abcam, Ltd., Cambridge, UK) was used to evaluate the effect of $\mathrm{OH}-\mathrm{dDHL}$ on the intracellular calcium mobilization in the BMDMs. The experiments were performed according to manufacturer's instructions with a minor modification. Briefly, BMDMs were cultured overnight with growth medium in 96-well plates. 
Then, cells were washed with Hanks' balanced salt solution to minimize background fluorescence and interference with serum. Cells were incubated with Fluo-8 AM for $1 \mathrm{~h}$ in HBSS prior to treatment with $\mathrm{OH}-\mathrm{dDHL}$ for the indicated dose. The cytoplasmic calcium level was documented by the fluorescence intensity under an SpectroMAX ELISA plate reader (Molecular Devices, San Jose, CA, USA). For the confocal microscopic analysis, cells were seeded onto glass coverslip in 12-well plates and treated with OH-dDHL in a dose-dependent manner. Cells were incubated with Fluo-8 AM for $1 \mathrm{~h}$ at $37^{\circ} \mathrm{C}$ in the dark and further fixed with $4 \%$ PFA. The coverslips were washed and mounted on microscope slides by using Vectashield mounting medium containing DAPI and stored at $4{ }^{\circ} \mathrm{C}$ in the dark. The stained samples were viewed with a Leica DMi8 confocal microscope (Leica Microsystems Ltd., Wetzlar, Germany).

\subsection{RNA Extraction, Revers Transcription, and Real-Time Quantitative PCR (RT-qPCR)}

Total RNA was extracted from OH-dDHL treated in BMDM using the RNeasy Mini kit (Qiagen, Venlo, Netherlands) in accordance with the manufacturer's protocol. cDNA was amplified by random hexamers using a Reverse Transcription premix (ElpisBio, Daejeon, Korea). Table 1 lists the primers used in the Polymerase Chain Reactions (PCRs). Quantitative PCR was carried out with cDNA in the CFX96 Real-time PCR detection system (Bio-Rad Hercules, CA, USA) with Prime Q-Mastermix with SYBR Green (GeNet Bio, Choenan, Korea) according to following conditions: (a) initial denaturation: $95{ }^{\circ} \mathrm{C}$ for $10 \mathrm{~min}$, (b) 40 cycles including denaturation $30 \mathrm{sec}$, annealing: $58^{\circ} \mathrm{C}$ for $30 \mathrm{sec}$, extension: $72{ }^{\circ} \mathrm{C}$ for $30 \mathrm{sec}$. The expression levels of the genes were normalized to GAPDH using the comparative quantitation cycle $(\mathrm{Cq})$ method $\left(2^{-\Delta \Delta \mathrm{Cq}}\right)$, as described by the CFX96 Real-time PCR detection system (CFX Maestro ${ }^{\text {TM }}$ Software, Bio-Rad Hercules, CA, USA). All RT-qPCR reactions were run in triplicate, and a non-template control was used for each run.

Table 1. Gene names and primer sequences (mouse) used in this study.

\begin{tabular}{ccc}
\hline Gene Name & Forward Primer & Reverse Primer \\
\hline TNF- $\alpha$ & AGGCACTCCCCCAAAAGATG & GTAGACAGAAGAGCGTGGTGG \\
\hline IL-1 $\beta$ & CAACAAGAGCTTCAGGCAGG & TGCTCATGTCCTCATCCTGG \\
\hline IL-6 & GTTGCCTTCTTGGGACTGAT & GGTATAGACAGGTCTGTTGG \\
\hline IL-8 & GCTACGATGTCTGTGTATTC & TCACTTCCTTTCTGTTGCAG \\
\hline MCP-1 & CCACTCACCTGCTGCTACTC & ACAGCTTCTTTGGGACACCT \\
\hline PON2 & CTAATGGACAGAGGCTCTTC & TACACCGTTGTCACTGATGG \\
\hline GAPDH & GTTCCAGTATGACTCCACTC & GTCTCGCTCCTGGAAGATGG \\
\hline
\end{tabular}

\subsection{Bacterial Invasion Assay}

BMDM cells were seeded $\left(1 \times 10^{6}\right.$ cells $\left./ \mathrm{mL}\right)$ in 12 -well plates containing DMEM supplemented with $10 \% \mathrm{FBS}$ and incubated at $37{ }^{\circ} \mathrm{C}$ in $5 \% \mathrm{CO}_{2}$ for $24 \mathrm{~h}$. Cultures of A. nosocomialis WT and anoI-deletion mutant strains were grown in LB broth overnight at $37^{\circ} \mathrm{C}$. Cells were infected with the bacterial cultures for $6 \mathrm{~h}$ at an MOI of 100. After incubation at the indicated condition, the cells were washed three times with DPBS before adding DMEM-FBS (10\%) containing $300 \mu \mathrm{g} / \mathrm{mL}$ of gentamicin to kill all external bacteria. Fresh DMEM medium was added and incubated for another $16 \mathrm{~h}$. The cells were washed with DPBS and lysed with $0.25 \%$ Triton X-100 at $37^{\circ} \mathrm{C}$ for $20 \mathrm{~min}$. Dilutions from each well were plated on LB agar plates and the colonies were counted to quantify the bacteria that had survived intracellularly.

\subsection{Animal Experiments}

Mice were purchased from Nara Biotech, Korea, and the animals were maintained under specific-pathogen-free conditions in accordance with the guidelines of the Institutional Animal Care and Use Committee (IACUC) of Chungnam National University 
(permission number: CNU-01182, Approval date: 26, Dec. 2018). The animal experiments were carried out in accordance with the Korean Food and Drug Administration guidelines. Seven-week-old female BALB/c mice were induced to neutropenic mice via intraperitoneal injections of cyclophosphamide $(150 \mathrm{mg} / \mathrm{kg})$ on days 4 and 1 prior to the injection of bacterial cells. The mice were anesthetized with tribromoethanol and groups of five were injected intratracheally with $50 \mu \mathrm{L}$ of $1 \times 10^{8} \mathrm{CFU} / \mathrm{mL}$ of bacteria. The control mice groups were injected with $50 \mu \mathrm{L}$ of sterilized PBS (pH 7.4). The mice were sacrificed three days after bacterial challenge and their lungs were excised to check for colonization efficiency. The lungs were washed with sterilized PBS and then homogenized. The cell suspension was serially diluted and spotted onto LB agar plates to count the bacteria. For histological analysis, the tissues were stained with hematoxylin/eosin, anti-COX-2, or immunohistochemical staining with OmpA antibody to visualize the bacteria.

\subsection{Data Analysis and Statistics}

Averages and standard errors of the means (SEM) were calculated from at least three independent experiments. All data were analyzed using unpaired Student's $t$-tests, oneway ANOVAs, and Tukey's multiple comparison test using statistical software (Graph Pad Prism Software, version 5.01; GraphPad Software, San Diego, CA, USA). Differences between experimental groups were considered to be significant at a $p$-value of $<0.05$, ${ }^{* *} p<0.01$, and ${ }^{* * *} p<0.001$.

Supplementary Materials: The following are available online at https:/ /www.mdpi.com/article/10 $.3390 / \mathrm{ijms} 22147565 / \mathrm{s} 1$.

Author Contributions: Conceptualization, K.W. and C.H.C.; methodology, K.W., D.H.K., M.H.O. and H.S.P.; formal analysis, K.W. and D.H.K.; data curation, K.W.; writing - original draft preparation, K.W. and C.H.C.; writing-review and editing, K.W., M.H.O. and C.H.C.; funding acquisition, C.H.C. All authors have read and agreed to the published version of the manuscript.

Funding: This work was supported by the National Research Foundation of Korea (NRF), a grant funded by the Korea government (MSIT) (NRF-2019R1F1A1043436, NRF-2019M3E5D1A02068575 (Bio and Medical Technology Development Program)), and the Basic Science Research Program through the National Research Foundation of Korea (NRF), funded by the Ministry of Education (NRF-2014R1A6A1029617).

Institutional Review Board Statement: The study was conducted according to the Institutional Animal Care and Use Committee (IACUC) of Chungnam National University guidelines (permission number: CNU-01182). The animal experiments were carried out in accordance with the guidelines of Korean Food and Drug Administration.

Informed Consent Statement: Not applicable.

Data Availability Statement: All data supporting the findings of this study are available within the paper and its supplementary materials published online.

Conflicts of Interest: The authors declare no conflict of interest.

\section{References}

1. Peleg, A.Y.; De Breij, A.; Adams, M.D.; Cerqueira, G.; Mocali, S.; Galardini, M.; Nibbering, P.H.; Earl, A.; Ward, D.V.; Paterson, D.; et al. The Success of Acinetobacter Species; Genetic, Metabolic and Virulence Attributes. PLoS ONE 2012, 7, e46984. [CrossRef]

2. Rocha, G.A.; Lima, D.F.; Rodrigues, E.R.; Leão, R.S.; Folescu, T.W.; Firmida, M.C.; Cohen, R.W.F.; Albano, R.M.; Marques, E.A. Species distribution, sequence types and antimicrobial resistance of Acinetobacter spp. from cystic fibrosis patients. Epidemiol. Infect. 2017, 146, 524-530. [CrossRef] [PubMed]

3. Lee, Y.-T.; Kuo, S.-C.; Yang, S.-P.; Lin, Y.-T.; Chiang, D.-H.; Tseng, F.-C.; Chen, T.-L.; Fung, C.-P. Bacteremic nosocomial pneumonia caused by Acinetobacter baumannii and Acinetobacter nosocomialis: A single or two distinct clinical entities? Clin. Microbiol. Infect. 2013, 19, 640-645. [CrossRef] [PubMed]

4. Liu, Y.-M.; Lee, Y.-T.; Kuo, S.-C.; Chen, T.-L.; Liu, C.-P.; Liu, C.-E. Comparison between bacteremia caused by Acinetobacter pittii and Acinetobacter nosocomialis. J. Microbiol. Immunol. Infect. 2017, 50, 62-67. [CrossRef] [PubMed]

5. Gowda, L.K.; Marie, M.A.M. Role of quorum-sensing molecules in infections caused by Gram-negative bacteria and host cell response. Rev. Med. Microbiol. 2014, 25, 66-70. [CrossRef] 
6. Bhargava, N.; Sharma, P.; Capalash, N. Quorum sensing in Acinetobacter: An emerging pathogen. Crit. Rev. Microbiol. 2010, 36, 349-360. [CrossRef]

7. Lade, H.; Paul, D.; Kweon, J.H. N-Acyl Homoserine Lactone-Mediated Quorum Sensing with Special Reference to Use of Quorum Quenching Bacteria in Membrane Biofouling Control. BioMed Res. Int. 2014, 2014, 1-25. [CrossRef] [PubMed]

8. Mayer, C.; Muras, A.; Romero, M.; López, M.; Tomas, M.; Otero, A. Multiple Quorum Quenching Enzymes Are Active in the Nosocomial Pathogen Acinetobacter baumannii ATCC17978. Front. Cell. Infect. Microbiol. 2018, 8, 310. [CrossRef]

9. Oh, M.H.; Choi, C.H. Role of LuxIR Homologue AnoIR in Acinetobacter nosocomialis and the Effect of Virstatin on the Expression of anoR Gene. J. Microbiol. Biotechnol. 2015, 25, 1390-1400. [CrossRef]

10. Saipriya, K.; Swathi, C.; Ratnakar, K.; Sritharan, V.; Kamaraju, S.; Ch, S. Quorum-sensing system in Acinetobacter baumannii: A potential target for new drug development. J. Appl. Microbiol. 2019, 128, 15-27. [CrossRef]

11. Erdönmez, D.; Rad, A.Y.; Aksöz, N. Quorum sensing molecules production by nosocomial and soil isolates Acinetobacter baumannii. Arch. Microbiol. 2017, 199, 1325-1334. [CrossRef] [PubMed]

12. Krzymińska, S.; Frąckowiak, H.; Kaznowski, A. Acinetobacter calcoaceticus-baumannii Complex Strains Induce Caspase-Dependent and Caspase-Independent Death of Human Epithelial Cells. Curr. Microbiol. 2012, 65, 319-329. [CrossRef] [PubMed]

13. Shames, S.R.; Finlay, B.B. Breaking the Stereotype: Virulence Factor-Mediated Protection of Host Cells in Bacterial Pathogenesis. PLoS Pathog. 2010, 6, e1001057. [CrossRef]

14. Lee, C.-R.; Lee, J.H.; Park, M.; Park, K.S.; Bae, I.K.; Kim, Y.B.; Cha, C.-J.; Jeong, B.C.; Lee, S.H. Biology of Acinetobacter baumannii: Pathogenesis, Antibiotic Resistance Mechanisms, and Prospective Treatment Options. Front. Cell. Infect. Microbiol. 2017, 7, 55. [CrossRef]

15. Morris, F.C.; Dexter, C.; Kostoulias, X.; Uddin, M.I.; Peleg, A.Y. The Mechanisms of Disease Caused by Acinetobacter baumannii. Front. Microbiol. 2019, 10, 1601. [CrossRef]

16. Choi, C.H.; Hyun, S.H.; Lee, J.Y.; Lee, J.S.; Lee, Y.; Kim, S.A.; Chae, J.-P.; Yoo, S.M.; Lee, J.C. Acinetobacter baumannii outer membrane protein A targets the nucleus and induces cytotoxicity. Cell. Microbiol. 2007, 10, 309-319. [CrossRef] [PubMed]

17. Jin, J.S.; Kwon, S.-O.; Moon, D.C.; Gurung, M.; Lee, J.H.; Kim, S.I.; Lee, J.C. Acinetobacter baumannii Secretes Cytotoxic Outer Membrane Protein A via Outer Membrane Vesicles. PLoS ONE 2011, 6, e17027. [CrossRef] [PubMed]

18. Kim, S.W.; Oh, M.H.; Jun, S.H.; Jeon, H.; Kim, S.I.; Kim, K.; Lee, Y.C.; Lee, J.C. Outer membrane Protein A plays a role in pathogenesis of Acinetobacter nosocomialis. Virulence 2016, 7, 413-426. [CrossRef]

19. Savitskaya, M.A.; Onishchenko, G.E. Mechanisms of apoptosis. Biochemistry 2015, 80, 1393-1405. [CrossRef]

20. Jorgensen, I.; Rayamajhi, M.; Miao, E.A. Programmed cell death as a defence against infection. Nat. Rev. Immunol. 2017, 17, 151-164. [CrossRef] [PubMed]

21. Redza-Dutordoir, M.; Averill-Bates, D.A. Activation of apoptosis signalling pathways by reactive oxygen species. Biochim. Biophys. Acta 2016, 1863, 2977-2992. [CrossRef]

22. Iurlaro, R.; Muñoz-Pinedo, C. Cell death induced by endoplasmic reticulum stress. FEBS J. 2016, 283, 2640-2652. [CrossRef] [PubMed]

23. Sano, R.; Reed, J.C. ER stress-induced cell death mechanisms. Biochim. Biophys. Acta 2013, 1833, 3460-3470. [CrossRef] [PubMed]

24. Jacobi, C.A.; Schiffner, F.; Henkel, M.; Waibel, M.; Stork, B.; Daubrawa, M.; Eberl, L.; Gregor, M.; Wesselborg, S. Effects of bacterial $\mathrm{N}$-acyl homoserine lactones on human Jurkat T lymphocytes-OdDHL induces apoptosis via the mitochondrial pathway. Int. J. Med. Microbiol. 2009, 299, 509-519. [CrossRef] [PubMed]

25. Glucksam-Galnoy, Y.; Sananes, R.; Silberstein, N.; Krief, P.; Kravchenko, V.V.; Meijler, M.M.; Zor, T. The Bacterial Quorum-Sensing Signal Molecule N-3-Oxo-Dodecanoyl-1-Homoserine Lactone Reciprocally Modulates Pro- and Anti-Inflammatory Cytokines in Activated Macrophages. J. Immunol. 2013, 191, 337-344. [CrossRef]

26. Stacy, D.M.; Welsh, M.; Rather, P.N.; Blackwell, H.E. Attenuation of Quorum Sensing in the Pathogen Acinetobacter baumannii Using Non-native N-Acyl Homoserine Lactones. ACS Chem. Biol. 2012, 7, 1719-1728. [CrossRef] [PubMed]

27. Losa, D.; Kohler, T.; Bacchetta, M.; Saab, J.B.; Frieden, M.; van Delden, C.; Chanson, M. Airway Epithelial Cell Integrity Protects from Cytotoxicity of Pseudomonas aeruginosa Quorum-Sensing Signals. Am. J. Respir. Cell Mol. Biol. 2015, 53, 265-275. [CrossRef]

28. Shih, D.M.; Lusis, A.J. The roles of PON1 and PON2 in cardiovascular disease and innate immunity. Curr. Opin. Lipidol. 2009, 20, 288-292. [CrossRef]

29. Eum, S.Y.; Jaraki, D.; Bertrand, L.; András, I.E.; Toborek, M. Disruption of epithelial barrier by quorum-sensing N-3(oxododecanoyl)-homoserine lactone is mediated by matrix metalloproteinases. Am. J. Physiol. Gastrointest. Liver Physiol. 2014, 306, G992-G1001. [CrossRef]

30. Tao, S.; Luo, Y.; He, B.; Liu, J.; Qian, X.; Ni, Y.; Zhao, R. Paraoxonase 2 modulates a proapoptotic function in LS174T cells in response to quorum sensing molecule $N$-(3-oxododecanoyl)-L-homoserine lactone. Sci. Rep. 2016, 6, 28778. [CrossRef]

31. Kobayashi, S.D.; Malachowa, N.; DeLeo, F.R. Neutrophils and Bacterial Immune Evasion. J. Innate Immun. 2018, 10 , $432-441$. [CrossRef]

32. García-Patiño, M.G.; García-Contreras, R.; Licona-Limón, P. The Immune Response against Acinetobacter baumannii, an Emerging Pathogen in Nosocomial Infections. Front. Immunol. 2017, 8, 441. [CrossRef] [PubMed]

33. Qiu, H.; KuoLee, R.; Harris, G.; Van Rooijen, N.; Patel, G.B.; Chen, W. Role of Macrophages in Early Host Resistance to Respiratory Acinetobacter baumannii Infection. PLoS ONE 2012, 7, e40019. [CrossRef] 
34. Lancellotti, M.; Pereira, R.F.C.; Cury, G.G.; De Hollanda, L.M. Pathogenic and opportunistic respiratory bacteria-induced apoptosis. Braz. J. Infect. Dis. 2009, 13, 226-231. [CrossRef] [PubMed]

35. Labbe, K.; Saleh, M. Cell death in the host response to infection. Cell Death Differ. 2008, 15, 1339-1349. [CrossRef] [PubMed]

36. Chow, S.H.; Deo, P.; Naderer, T. Macrophage cell death in microbial infections. Cell. Microbiol. 2016, 18, 466-474. [CrossRef] [PubMed]

37. Tateda, K.; Ishii, Y.; Horikawa, M.; Matsumoto, T.; Miyairi, S.; Pechere, J.C.; Standiford, T.J.; Ishiguro, M.; Yamaguchi, K. The Pseudomonas aeruginosa Autoinducer N -3-Oxododecanoyl Homoserine Lactone Accelerates Apoptosis in Macrophages and Neutrophils. Infect. Immun. 2003, 71, 5785-5793. [CrossRef]

38. Taguchi, R.; Tanaka, S.; Joe, G.-H.; Maseda, H.; Nomura, N.; Ohnishi, J.; Ishizuka, S.; Shimizu, H.; Miyazaki, H. Mucin 3 is involved in intestinal epithelial cell apoptosis via $\mathrm{N}$-(3-oxododecanoyl)-L-homoserine lactone-induced suppression of Akt phosphorylation. Am. J. Physiol. Cell Physiol. 2014, 307, C162-C168. [CrossRef]

39. Szegezdi, E.; Fitzgerald, U.; Samali, A. Caspase-12 and ER-stress-mediated apoptosis: The story so far. Ann. N. Y. Acad. Sci. 2003, 1010, 186-194. [CrossRef]

40. Schwarzer, C.; Fu, Z.; Shuai, S.; Babbar, S.; Zhao, G.; Li, C.; Machen, T.E. Pseudomonas aeruginosa homoserine lactone triggers apoptosis and Bak/Bax-independent release of mitochondrial cytochrome C in fibroblasts. Cell. Microbiol. 2014, 16, 1094-1104. [CrossRef]

41. Schwarzer, C.; Fu, Z.; Patanwala, M.; Hum, L.; Lopez-Guzman, M.; Illek, B.; Kong, W.; Lynch, S.V.; Machen, T.E. Pseudomonas aeruginosa biofilm-associated homoserine lactone C12 rapidly activates apoptosis in airway epithelia. Cell. Microbiol. 2012, 14, 698-709. [CrossRef] [PubMed]

42. Olsson, S.; Sundler, R. The role of lipid rafts in LPS-induced signaling in a macrophage cell line. Mol. Immunol. 2006, 43, 607-612. [CrossRef] [PubMed]

43. Schwarzer, C.; Fu, Z.; Morita, T.; Whitt, A.G.; Neely, A.M.; Liu, Y.; Machen, T.E.; Sun, B.; Xiao, Z.; Wang, R.; et al. Paraoxonase 2 Serves a Proapopotic Function in Mouse and Human Cells in Response to the Pseudomonas aeruginosa quorum-sensing Molecule N-(3-Oxododecanoyl)-homoserine Lactone. J. Biol. Chem. 2015, 290, 7247-7258. [CrossRef]

44. Nho, J.S.; Jun, S.H.; Oh, M.H.; Park, T.I.; Choi, C.W.; Kim, S.I.; Choi, C.H.; Lee, J.C. Acinetobacter nosocomialis secretes outer membrane vesicles that induce epithelial cell death and host inflammatory responses. Microb. Pathog. 2015, 81, 39-45. [CrossRef] [PubMed]

45. Brossard, K.A.; Campagnari, A.A. The Acinetobacter baumannii Biofilm-Associated Protein Plays a Role in Adherence to Human Epithelial Cells. Infect. Immun. 2012, 80, 228-233. [CrossRef] [PubMed]

46. Tang, R.; Zhu, J.; Feng, L.; Li, J.; Liu, X. Characterization of LuxI/LuxR and their regulation involved in biofilm formation and stress resistance in fish spoilers Pseudomonas fluorescens. Int. J. Food Microbiol. 2019, 297, 60-71. [CrossRef]

47. Zhu, Y.L.; Hou, H.M.; Zhang, G.L.; Wang, Y.F.; Hao, H.S. AHLs Regulate Biofilm Formation and Swimming Motility of Hafnia alvei H4. Front. Microbiol. 2019, 10, 1330. [CrossRef]

48. Lee, J.; Wu, J.; Deng, Y.; Wang, J.; Wang, C.; Wang, J.; Chang, C.; Dong, Y.; Williams, P.; Zhang, L.H. A cell-cell communication signal integrates quorum sensing and stress response. Nat. Chem. Biol. 2013, 9, 339-343. [CrossRef]

49. Horke, S.; Xiao, J.; Schutz, E.M.; Kramer, G.L.; Wilgenbus, P.; Witte, I.; Selbach, M.; Teiber, J.F. Novel Paraoxonase 2-Dependent Mechanism Mediating the Biological Effects of the Pseudomonas aeruginosa Quorum-Sensing Molecule N-(3-Oxo-Dodecanoyl)-LHomoserine Lactone. Infect. Immun. 2015, 83, 3369-3380. [CrossRef]

50. Oh, M.H.; Lee, J.C.; Kim, J.; Choi, C.H.; Han, K. Simple Method for Markerless Gene Deletion in Multidrug-Resistant Acinetobacter baumannii. Appl. Environ. Microbiol. 2015, 81, 3357-3368. [CrossRef]

51. Subhadra, B.; Surendran, S.; Kim, D.H.; Woo, K.; Oh, M.H.; Choi, C.H. The transcription factor NemR is an electrophile-sensing regulator important for the detoxification of reactive electrophiles in Acinetobacter nosocomialis. Res. Microbiol. 2019, 170, 123-130. [CrossRef] [PubMed] 